\title{
Mapping the Competencies of Design Engineers Against the Jantsch's Hierarchical System
}

\author{
Jana SAJDAKOVA ${ }^{1}$, Linda NEWNES, Emily CAREY and Vimal DHOKIA \\ Mechanical Engineering, University of Bath, UK
}

\begin{abstract}
Presented in this paper are the results of a systematic literature review to identify the competencies required by design engineers to work in increasingly complex societal projects. These competencies are then mapped against the four levels of a hierarchical system defined by Jantsch to ascertain the disciplinarity of these competencies. The results from this mapping form the first phase in the creation of a Designer Readiness Level for transdisciplinary engineering. To date current research has identified that to meet these future needs, defined as Grand Challenges for Engineering by the National Academy of Engineering, it will be necessary to adopt transdisciplinary methods of working. However, there is little in the literature that identifies how to assess the transdisciplinarity of people, tools or project teams. Although literature and learned societies do highlight that engineers are crucial to meet these societal needs, how do we determine whether an engineer is able to work in a transdisciplinary manner? A total of 2398 papers were included in the review and twenty-nine papers selected for full-text review. A final seven focussing on practicing design engineers were used to create a current list of competencies. The paper continues by describing the analysis method and results of mapping the competencies identified against Jantsch's four levels. The paper concludes with a summary of the next stage required to create a Designer Readiness Level for transdisciplinary engineering.
\end{abstract}

Keywords. Transdisciplinarity, Transdisciplinary Research, Transdisciplinary Engineering Research, Design Engineer, Competencies

\section{Introduction}

As the global population grows, concerns about environmental issues and the unsustainable use of the world's resources are increasing [1,2]. The National Academy of Engineering (NAE) committee in 2012 identified 14 Grand Challenges for Engineering which are critical to sustaining continuous advancement of humanity e.g. make solar energy economical, engineer better medicines, provide energy from fusion. With engineers being integral to creating innovative products that improve quality of life [3] and advance society in a sustainable way [1]. These grand challenges can be defined as complex problems that require involvement of a wide range of stakeholders [3].

A transdisciplinary (TD) approach is hypothesised to offer a higher level of analysis compared to other disciplinarities [4] and hence may well be the right approach to tackle complex engineering challenges. TD has already been used in context of "wicked" -

\footnotetext{
${ }^{1}$ Corresponding Author, Mail: js3444@bath.ac.uk.
} 
large, complex and ill-defined problems that require involvement from a range of disciplines working towards a common goal [5]. In order to achieve societally focused or transdisciplinary engineering (TE), design engineers will require the dynamic acquisition of specific competencies.

The competencies design engineers may require for TE is the focus of this paper. The aim of the review and secondary analysis is to compile and map competencies to identify if any are more required for TE. To do this we answer, three research questions:

$R Q 1$. What evidence is in the literature regarding competencies related to design engineers?

RQ2. Can these identified competencies be classified into disciplinary competencies?

RQ3. Do any of the identified competencies have TD attributes?

The paper is structured as follows: section 1 provides a motivation for selecting competencies related to design engineers. In section 2, Jantsch's TD hierarchical system providing the framework for this study is described. A methodology follows in section 3 ; with the results being presented in section 4. A competence classification model is then proposed in section 5; this is followed by a discussion in section 6 . Finally, the implications of the results and future research are discussed in the conclusion.

\section{Design Engineers and Competencies}

Blessing, Pahl and Wallace [6] use the terms designer, design and development engineer interchangeably to describe engineers involved in the creative aspects of a product life cycle, in the context of this study we use term design engineer. Much of engineering design research has sought to understand how engineers spend their time, with traditional thought being that engineers are purely technical with $100 \%$ of their time allocated within steps of the design process. Whereas later research found that technical work only takes up $47 \%$ of a typical designer's time [7], and that while technical competencies are important, they are inseparable from social competencies linked to effective collaboration [8].

Since designers are increasingly more often collaborating in design activities using complex working environments involving a variety of different actors and cultures [9] they are hence relying on a range of non-technical skills in particular, communication [8]. Other collaboration skills such as team-working skills, intercultural communication and knowledge management are becoming indispensable.

The definition of the term competency used in this paper refers to a capacity to effectively perform both task and role and is linked to the individual's skills, knowledge, motives, values and personal traits $[7,10]$.

While a large body of research focuses on competency requirements of engineers $[7,8]$, there is a lack of studies specifically focusing on design engineers [7], even though it is estimated that over $70 \%$ of the product development life-cycle cost is embedded in the design conception phase [11]. It is also notable that a large part of engineering competence literature focuses upon engineering education, specifically to close gaps between skills acquired in higher education and skills required by industry $[8,12]$. However, to make an effective TD design engineer it will require competencies beyond those acquired in higher education, and will require a life-long professional development in order to deal with evolving challenges linked to TD projects [5]. 
Predicting the competencies required by future design engineers to be able to work in a TE manner provides a significant design engineering research opportunity and is the purpose of the author's $\mathrm{PhD}$. To enable this, we require a structured approach to classify the disciplinarity of engineering competencies.

\section{Jantsch's TD System}

The TD term was first proposed by Jantsch at a conference in 1970, as a hierarchical multi-level, multi-goal education and innovation framework, for an education system [13]. This was chosen to map a designer's competencies because the framework is the original TD model [14] and can be operationalised [15]. The framework (Figure 1) consists of four levels: empirical, pragmatic, normative and purposive. The base of the pyramid is the empirical level, composed of individual scientific disciplines i.e. physics. The pragmatic level contains applied sciences, where theories from the empirical level are applied in individual disciplines i.e. engineering. Above this is the normative level which represents social systems constructs such as norms, laws and regulations. At the top of the pyramid, sits the purposive level with societal values and meanings.

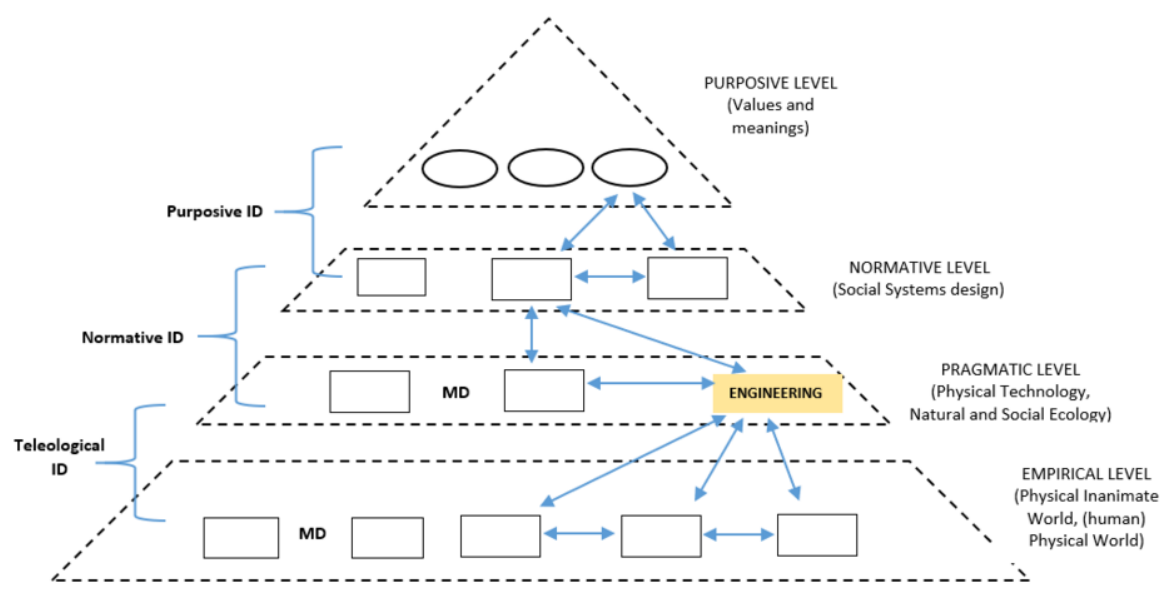

Figure 1. Multi-level, multi-goal, hierarchical system adapted from [13].

Different types of co-ordination and co-operation take place across the levels, involving the interaction of different actors. Jantsch defines five disciplinary ways of cooperation and co-ordination: multidisciplinarity (MD), pluridisciplinarity, crossdisciplinarity, interdisciplinarity (ID) and transdisciplinarity (TD). He further divides ID into teleological ID, normative ID and purposive ID, to describe the levels amongst which they interact (shown in Figure 1).

Table 1 defines and illustrates the interactions in disciplinarities, where TD is deemed the highest level of disciplinarity. In TD all levels of the system interact together, with all disciplines and interdisciplines, being co-ordinated in a top-down manner from the purposive level to pursue a common system goal [13]. Each disciplinarity shown refers to a distinct disciplinary organisation and way of working. We argue that by asking questions based on the definition of each level, it is possible to identify and link specific competencies to each level. 
Table 1. Jantsch's definitions of disciplinarity.

\begin{tabular}{ll}
\hline Disciplinarity & Definition \\
\hline $\begin{array}{l}\text { Multi, pluri and } \\
\text { crossdisciplinarity } \\
\text { (MD)* }\end{array}$ & One level, variety of disciplines, no co-operation \\
Interdisciplinarity & $\begin{array}{l}\text { A common axiomatics for a group of related } \\
\text { disciplinas is defined at the next higher hierarchical } \\
\text { level or sub-level, thereby introducing a sense of } \\
\text { purpose } \\
\text { The co-ordination of all disciplines and interdisciplines } \\
\text { in the education/innovation system on the basis of a } \\
\text { generalized axiomatics (introduced from the purposive } \\
\text { level) and an emerging epistemological pattern }\end{array}$ \\
Transdisciplinarity
\end{tabular}

(*) Within this paper MD for the purpose of mapping encompasses pluri, cross and multidisciplinarity

Section 3 provides the methodology for identifying the relevant literature to find evidence regarding competencies relevant to design engineers.

\section{Methodology}

The aim of this research was to identify and characterise, in disciplinary terms, the design engineers' competencies within published literature. The review strategy follows the steps of a systematic literature review (SLR) process outlined by Tranfield [16]. As a part of this process the authors formed a review panel to recommend relevant literature, formulate research questions and make literature inclusion/exclusion decisions [16].

An initial exploratory investigation of research related to engineer's competencies elicited the terms "engineer", "competence" and "skill", being expanded to the following keyword selection for searching literature: competence, ability, skill, capability, behaviour, knowledge and attitude in title, abstract and keywords (Table 2).

Table 2. Search strategy.

\begin{tabular}{c} 
"Design engineer" \\
AND \\
competenc* OR abilit* OR skill OR sababilit* OR behaviour OR knowledge OR attitude \\
\hline
\end{tabular}

There are limitations to using specific keywords or single literature databases. Using the term "design engineer" may miss some literature not explicitly using this term, however, it is necessary due to the large volume of results to adopt a pragmatic approach to the inclusion of appropriate search term and literature resources. The electronic database SCOPUS was selected as it provides a characteristic sample of broad trends in research and covers a wider range of publications compared to the Web of Science [17]. The search resulted in a total of 2398 documents encompassing a broad range of literature from sciences, energy, social sciences to business, management and accounting due to the current ID nature of engineering research [6,8]. As per Tranfield [16], the different phases of the SLR are summarised in the process flow diagram in Table 3.

Table 3. Literature search process.

Scopus keyword literature search results $\mathrm{n}=2398$ 


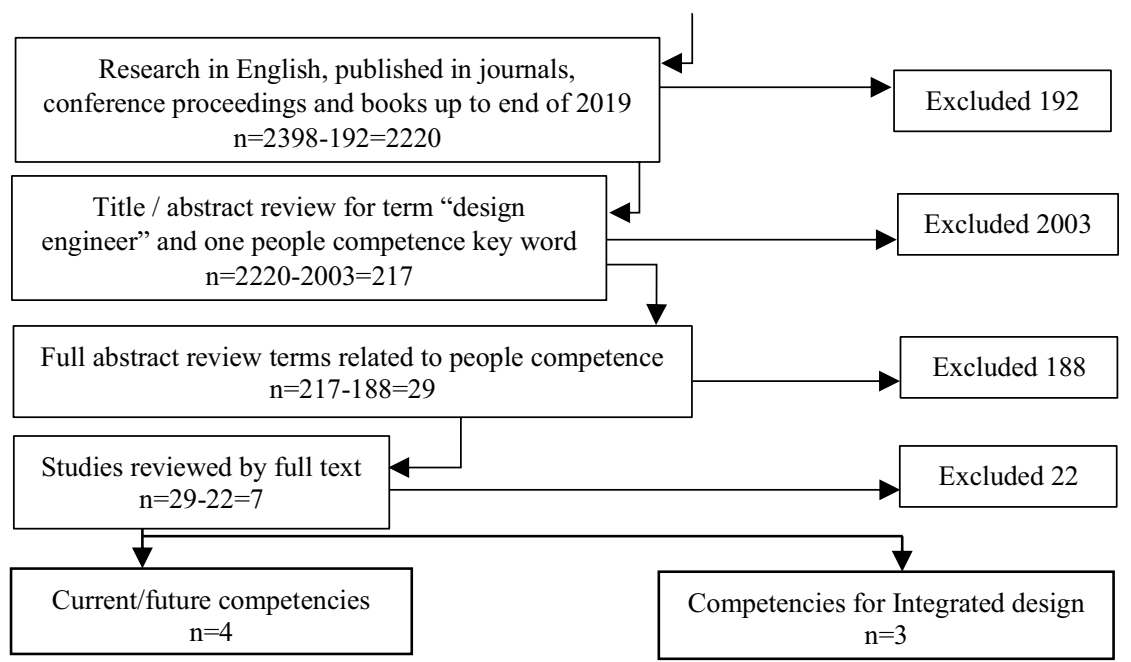

Seven papers addressing specific competence or skill profiles related to design engineers were relevant to our analysis. Based on their research focus they were classified into two categories (Table 3), four studies S1, S2, S6 and S7 focus on current or future competencies and studies S3, S4 and S5 focus on integrated design competencies in relation to the European certification scheme (Table 4).

Table 4. Literature Focus.

\begin{tabular}{lll}
\hline Study & Focus & \multicolumn{1}{c}{ Reference } \\
\hline S1 & Future competency profile & Robinson et al., 2005[7] \\
S2 & Current competencies - Knowledge classification & Ahmed, 2007[10] \\
S3 & Integrated design competencies & Riel et al., 2009[18] \\
S4 & Integrated design competencies & Riel et al., 2010 [19] \\
S5 & Integrated design competencies & Riel et al., 2012 [11] \\
S6 & Current competency profile & Abbas et al., 2013 [12] \\
S7 & Current competencies - Innovation competencies & Birdi, Leach and Magadley, 2016 [20] \\
\hline
\end{tabular}

To provide a systematic approach to analysing qualitative data, the thematic analysis method allowed for integration of competency data from the seven papers for further analysis [21]. Based on the way the data was provided the data extraction methods vary [21]. Data in papers S1, S5, S6 were extracted using a semantic approach directly from listed competency profiles. Data were extracted using a latent approach from text only in S3, S4 and S7. While, in S2 data was identified using a mix of both approaches.

\section{Results}

Paper S1 used a three-phase methodology to compile a list of 42 future competencies divided into six groups. S2 is an empirical study classifying types of knowledge and the time it takes to become an expert in a competence. The paper focuses on procedural knowledge and does not list all identified types of knowledge, with only twelve explicitly listed. In addition, eight personal attributes were identified, and another 18 skills were extracted from the text. S3, S4 and S5 are a series of studies concerned with life-long learning, they examine integrated design competencies in order to create industry driven training for European Certificates and the Qualification Association. S6 identifies 75 competencies required by design engineers in Pakistan and describes a competency 
development and enhancement model. S7 is a qualitative study of 169 design engineers examining the relationship of individual competencies and innovative behaviour.

The papers were published between 2005 and 2016, which may not relate closely to important current competencies as even the most recent is 4 years old. The $\mathrm{S} 1$ study from 2005 provides future competency profiles looking ten years into the future placing it into 2015. Compared to S6's 2013 competency profile which identifies more competencies, both produce very similar competencies, meaning that S1's futuristic view could be deemed a good representation.

Interestingly IT skills are only discussed in the oldest study S1 and this is only generically. It is notable as literature identifies a growing need for competencies related to digital technologies that will allow engineers to work with networked manufacturing technologies in automated environments; as well as analyse and understand large volumes of complex data produced by these automated environments [5, 22].

Each study provides a different depth of detail when describing competencies from very generic in S1 to a more detailed contextual description in S5. According to Ahmed [10] competencies must have a context thus those competencies with more detail provide richer data for the next stage of analysis. The competencies from seven papers were compiled to a profile containing 117 competencies divided into several groups such as personal attributes, cognitive strategies, technical skills, communication and collaboration competencies. To answer RQ2 and RQ3 these 117 competencies were individually mapped against the TD framework.

\section{Mapping competencies against the Jantsch's hierarchical system}

In order to map designer competencies according to different types of co-ordination as illustrated in Figure 1, we describe what working at each level would look like for design engineers based on Jantsch's definitions. A model for classifying disciplinary competencies is proposed in Table 5, by formulating two questions for each level of working to describe the nature of interactions.

Engineering design as an applied science sits within the pragmatic level and interacts with sciences at the empirical level (Jantsch defines as teleological ID). Competencies related to Jantsch's definition of teleological ID are linked to the capitalisation of scientific knowledge from an empirical level and applying this to engineering tasks. Thus, by asking two question related to teleological ID as presented in Table 5 these types of competences can be identified.

Table 5. Competence classification method.

\begin{tabular}{|c|c|c|c|c|}
\hline Multidisciplinarity & $\begin{array}{l}\text { Teleological } \\
\text { Interdisciplinarity }\end{array}$ & $\begin{array}{l}\text { Normative } \\
\text { Interdisciplinarity }\end{array}$ & Transdisciplinarity & $\begin{array}{l}\begin{array}{l}\text { General } \\
\text { competencies }\end{array} \\
\end{array}$ \\
\hline $\begin{array}{l}\text { Is the competence } \\
\text { necessary for } \\
\text { working in } \\
\text { disciplinary } \\
\text { isolation? }\end{array}$ & $\begin{array}{l}\text { Does the } \\
\text { competence enable } \\
\text { capitalization of } \\
\text { scientific } \\
\text { knowledge from } \\
\text { empirical level? }\end{array}$ & $\begin{array}{l}\text { Does the } \\
\text { competence } \\
\text { demonstrate } \\
\text { knowledge of rule } \\
\text { and norms? }\end{array}$ & $\begin{array}{l}\text { Does the } \\
\text { competence } \\
\text { demonstrate } \\
\text { purpose } \\
\text { consideration? }\end{array}$ & $\begin{array}{l}\text { Is the } \\
\text { competence } \\
\text { necessary for } \\
\text { working in } \\
\text { any job? }\end{array}$ \\
\hline $\begin{array}{l}\text { Does the } \\
\text { competence enable } \\
\text { awareness or } \\
\text { experience of other } \\
\text { disciplines without }\end{array}$ & $\begin{array}{l}\text { Is the competence } \\
\text { necessary for } \\
\text { working in } \\
\text { engineering }\end{array}$ & $\begin{array}{l}\text { Does the } \\
\text { competence enable } \\
\text { working with } \\
\text { experts from other } \\
\text { disciplines/ }\end{array}$ & $\begin{array}{l}\text { Does the } \\
\text { competence } \\
\text { demonstrate value } \\
\text { recognitions? }\end{array}$ & $\begin{array}{l}\text { Would the } \\
\text { competence } \\
\text { be in a job } \\
\text { description for } \\
\text { most jobs? }\end{array}$ \\
\hline
\end{tabular}




\begin{tabular}{lll}
\hline integration of & discipline on & stakeholders from \\
knowledge? & engineering task? & outside science?
\end{tabular}

MD relates to a design engineer working within the engineering discipline, in isolation from other applied disciplines. They may have experience or awareness of other departments or disciplines, but that knowledge does not translate to their work. In practice it requires mostly the same competencies as teleological ID.

Normative ID refers to engineering interacting with other applied sciences on the pragmatic level while adhering to norms, rules and policies set at the higher - normative level. It includes design engineers whose role is the development of technological alternatives e.g. innovative technology. Competencies relevant to this level of working cross the normative level boundary and allow design engineers to co-operate with a wide range of stakeholders and recognise different points of view and requirements.

Purposive ID only crosses normative and purposive levels without integrating scientific disciplines, thus is not applicable to engineering. The TD level can be achieved by integrating all other levels: it is about the interactions up and down and across all levels of the pyramid; between disciplines, across project boundaries, between academia and industry while the purpose is incorporated across all levels of the pyramid. Competencies relevant to TD will enable the integration of requirements and values of different stakeholders by recognising the purpose.

Table 6: Disciplinary competencies.

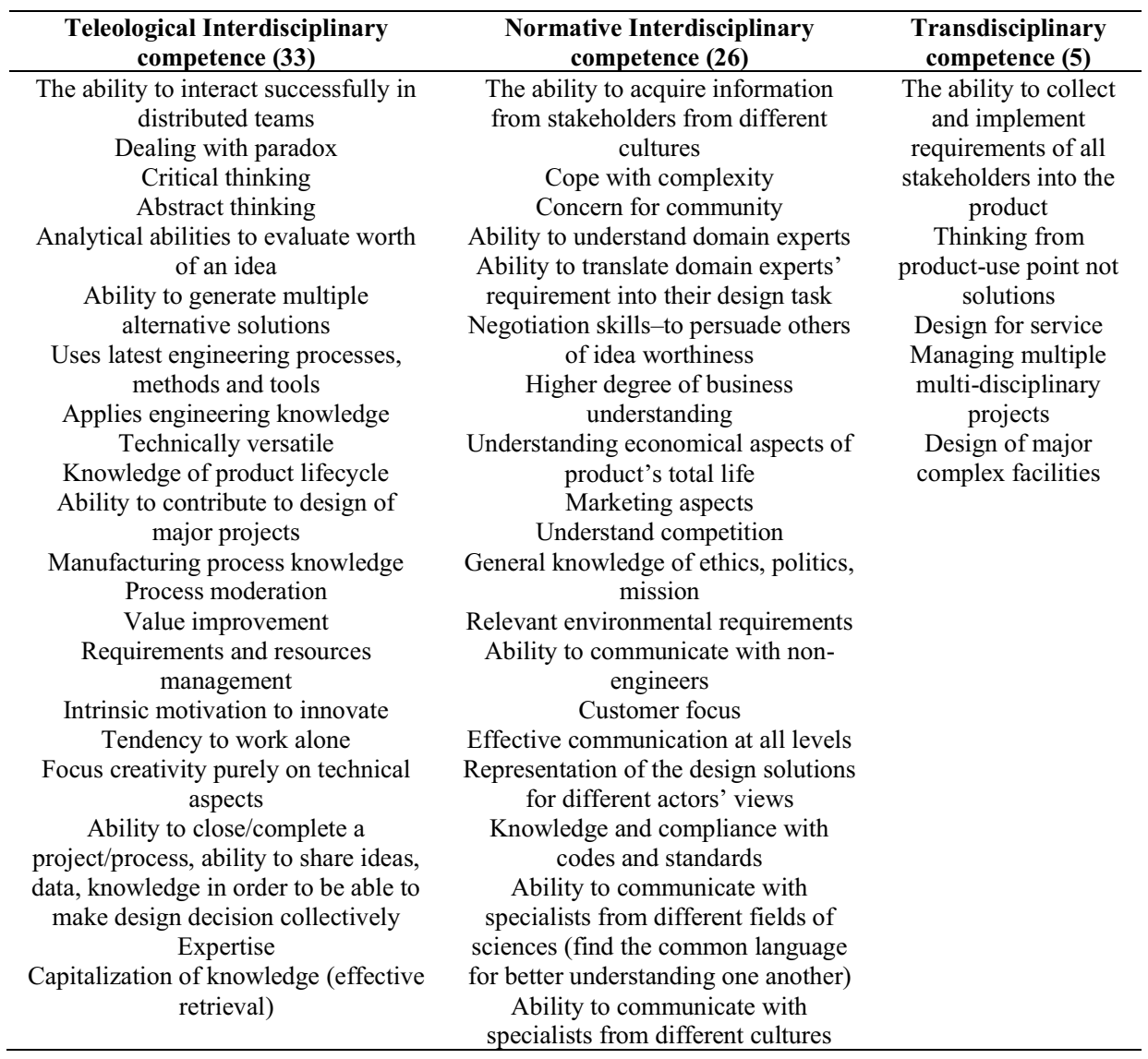




\begin{tabular}{cc}
\hline $\begin{array}{c}\text { Ability to lead in an engineering } \\
\text { discipline }\end{array}$ & $\begin{array}{c}\text { (avoid misunderstanding, } \\
\text { miscommunication) } \\
\text { Awareness that integrated } \\
\text { Formalization of knowledge-using } \\
\text { right methods to capture knowledge } \\
\text { Professional ethics }\end{array}$ \\
$\begin{array}{c}\text { stakeholders have different } \\
\text { expectation, preferences and } \\
\text { constraints }\end{array}$ \\
distributed teams & $\begin{array}{c}\text { Intercultural skills required for } \\
\text { Memories of previous projects } \\
\text { Ability to use tools for collaborative } \\
\text { design }\end{array}$ \\
$\begin{array}{c}\text { essential entities to be integrated into } \\
\text { the holistic design process as a }\end{array}$ \\
prerequisite to understand different \\
approaches \\
teams
\end{tabular}

This model assisted with finding disciplinary competencies (Table 6) to answer RQ3, by answering yes or no to one or both questions. In summary we found three MD competencies, 33 Teleological ID competencies, 26 Normative ID competencies and five TD competencies. The remaining 50 competencies have no disciplinarity or lack context and hence were unable to be clearly classified based on disciplines.

\section{Discussion}

We answered RQ2 and identified competencies based on disciplinarity. Mapping identified three MD competencies: manage multi-disciplinary teams; understanding organisational dynamics and central/head office experience. They relate to awareness or experience of other departments within their own organisation, but without co-operation or integration of the knowledge.

The largest group is Teleological ID competencies. This is not surprising as this group represents competencies related to technical aspects of the design engineer's role. By asking "Is competence necessary for working in the engineering discipline on engineering tasks?" we were able to map all technical and design process skills to this level. Other competencies related to design task include cognitive abilities such as critical thinking, abstract thinking, and analytical abilities to evaluate an idea.

The second largest group are Normative ID competencies. Included competencies focus on awareness of different stakeholders, knowledge of the wider business environment and knowledge and compliance with codes and standards. One competence describes a tendency to work alone, focusing creativity purely on technical aspects, such preference can be a good indication if the person is suitable to work in TD manner.

Asking "Is purpose / value considered?"; "Does competence demonstrate purpose / value recognition?" helped to answer RQ3 and identify five TD competencies shown in Table 6. The first two competencies relate to an engineer's ability to think from a stakeholder perspective, how and for what purpose they use a product/service, and what value are they getting from its use. The third competence implies awareness of other stakeholders' requirements, but only by implementing these requirements the purpose is recognised. Competencies four and five imply understanding of complexity, purpose and value of the project.

The group of generic competencies include mainly personal attributes, cognitive strategies and abilities, but also basic communication competencies. Although, they are important to design engineering, they relate to basic skills relevant to any job. Competencies include self-motivation, personal honesty, career ambition and ability to adapt to change. 
Although mapping decisions mentioned above are subjective and interpretations of competencies may vary, what is clear from this analysis is that the context is important for disciplinary classification. For instance, general competence inter-cultural communication, with context translates to disciplinary competence at all levels (first entry in Table 6).

The TE working relates to collaboration of a range of stakeholders on a complex problem that cannot be solved by a single discipline, with purpose considered across all levels. This indicates that in order for engineers to work in this way normative ID competencies are important such as, the ability to communicate and co-operate with a range of stakeholders from outside sciences and across different cultures, understanding self and the wider societal environments, and understanding different points of view. But what takes competencies to the TD level is the ability to consider the range of values and integrate these into the solution. This may require the change of thinking in order to incorporate purpose and value into design engineer's work.

\section{Conclusion}

This paper presents the results of an SLR to identify competencies required by design engineers. The review demonstrates that although the role of design engineers is crucial to the product development process and to meet future societal needs, there is a gap in current designer competency profiles. The first phase in the creation of a Designer Readiness Level for transdisciplinary working was to map the identified competencies against the levels of the Jantsch's hierarchical framework. The results from this mapping show that while many competencies lack context making it difficult to classify, five competencies were found showing TD attributes and 26 competencies showing normative ID attributes. This is important when thinking of competency requirements for future TE projects. Education and training for design engineers will need to reflect this necessity to acquire not only TD competencies but also competencies related to the collaboration with a range of stakeholders from outside sciences and across different cultures as well as understanding the self and the wider societal environments. The focus of future research and the next step in the creation of a Designer Readiness Level will be to determine the way to measure current competency levels against TE competency requirements for $\mathrm{TE}$ projects in order to identify gaps in training and curricula requirements.

\section{References}

[1] P. Brandt, A. Ernst, F. Gralla, C. Luederitz, D. Lang, J. Newig, F. Reinert, D. Abson and H. Von Wehrden, A review of transdisciplinary research in sustainability science. Ecological Economics, vol. 92, 2013, pp. $1-15$.

[2] World Bank, World Development Report 2019: The changing nature of work, Washington, DC, World Bank, 2019, pp 321-330.

[3] National Academy of Engineering, 2012, 14 Grand Challenges for Engineering in 21st Century: Introduction to the Grand Challenges for Engineering, Accessed: 16.12.2019. [Online], Available: $\mathrm{http} / /$ www.engineeringchallenges.org/challenges.aspx.

[4] S. Lattanzio, E. Carey, A. Hultin, R. Imani Asrai, M. McManus, N. Mogles, G. Parry and L.B. Newnes, Transdisciplinarity Within the Academic Engineering Literature, International Journal of Agile Systems and Management, 2020, Vol. 13, No. 2, pp. 213-232.

[5] N. Wognum, C. Bil, F. Elgh, M. Peruzzini, J. Stjepandic and W. Verhagen, Transdisciplinary engineering research challenges, Advances in Transdisciplinary Engineering, Vol. 7, 2018, pp. 753-762. 
[6] L. Blessing, G. Pahl, and K. Wallace, Engineering design : a systematic approach. Springer, $3^{\text {rd }}$ ed, London, 2007.r

[7] M. Robinson, P. Sparrow, C. Clegg, K, Birdi, Design engineering competencies: Future requirements and predicted changes in the forthcoming decade. Design Studies, vol. 26(2), 2005, pp. 123-153.

[8] H. Passow and C. Passow, What Competencies Should Undergraduate Engineering Programs Emphasize? A Systematic Review. Journal Of Engineering Education, vol. 106(3), 2017, pp. 475-526.

[9] B. Robertson, J. Walther, and D. Radcliffe, Creativity and the use of CAD tools: Lessons for engineering design education from industry. Journal of Mechanical Design, Transactions of the ASME, vol. 129(7), 2007, pp. 753-760.

[10] S. Ahmed, S., An industrial case study: Identification of competencies of design engineers. Journal of Mechanical Design, Transactions of the ASME, vol. 129(7), 2007, pp. 709-716.

[11] A. Riel, A. Draghici, G. Draghici, D. Grajewski, R. Messnarz, Process and product innovation needs integrated engineering collaboration skills. Journal of software: Evolution and Process, vol. 24(5), 2012, pp. 551-560.

[12] A. Abbas, M. Choudhary, and N. Khan, An assessment of competency requirements of design engineers in Pakistan and development of a framework for improvement, Conference: Technology Management in the IT-Driven Services (PICMET), 2013 Proceedings of PICMET '13, 2013, pp. 1723-1737.

[13] E. Jantsch, Inter- and transdisciplinary University: A Systems Approach to Education and Innovation, Policy Sciences, Vol 1, 1970, pp. 7-37.

[14] C. Mitchell, D. Cordell, and D. Fam, Beginning at the end: The outcome spaces framework to guide purposive transdisciplinary research. Futures, Vol. 65(C), 2015, pp. 86-96.

[15] N. Mogles, S. Lattanzio, E. Carey, A. Kharlamov, G. Parry and L.B. Newnes, Classifying Disciplinarity of Engineering Academic Literature, In: The 27th Transdisciplinary Engineering Conference (TE2020), Warsaw, 2020

[16] D. Tranfield, D. Denyer, and P. Smart, Towards a Methodology for Developing Evidence-Informed Management Knowledge by Means of Systematic Review. British Journal of Management, 2003. vol 14(3), pp. 207-222.

[17] A. Aghaei Chadegani, H. Salehi, M. Yunus, H. Farhadi, M.Fooladi, M. Farhadi and N. Ale Ebrahim, A Comparison between Two Main Academic Literature Collections: Web of Science and Scopus Databases. Asian Social Science, 2013, vol. 9(5), pp. 18-26

[18] A. Riel, S. Tichkiewitch and R. Messnarz, Integrated engineering skills for improving the system competence level. Software Process: Improvement and Practice, vol. 14(6), 2009, pp. 325-335.

[19] Riel, A., S. Tichkiewitch, and R. Messnarz, Qualification and certification for the competitive edge in Integrated Design. CIRP Journal of Manufacturing Science and Technology, vol. 2(4), 2010, pp. 279289.

[20] K. Birdi, D. Leach, and W. Magadley, The Relationship of Individual Capabilities and Environmental Support with Different Facets of Designers' Innovative Behavior. Journal of Product Innovation Management, vol. 33(1), 2016, pp. 19-35.

[21] M. Saunders, P. Lewis and A. Thornhill, Research methods for business students, Pearson, $8^{\text {th }}$ ed, Harlow 2019.

[22] FISITA, 2018, Mobility Engineer 2030 White Paper, Accessed: 15.12.2019. [Online], Available: https://www.fisita.com/documents/FISITA_White_Paper_Mobility_Engineer_2030.pdf 